\title{
APRESENTAÇÃO: POLÍTICAS DE QUALIFICAÇÃO E O ESVAZIAMENTO DO DIREITO À EDUCAÇÃO'
}

Marcelo Lima ${ }^{2}$

A partir do ano de 2018 a Revista Trabalho Necessário passou a editar números temáticos coordenados por grupos de pesquisa associados ao NEDDATE, considerando sua afinidade com a linha editorial da revista, - o materialismo histórico. Assim, como meio de veiculação e mediação do pensamento crítico em relação ao mundo do trabalho, à formação humana e as relações históricas entre trabalho e educação, os números vêm sendo constituídos por artigos de autores convidados, vinculados a temática específica, além de artigos de demanda espontânea.

No número 30 (maio/agosto/2018), de acordo com o tema dos projetos e programas de formação humana, o NEDDATE em articulação com grupo de pesquisa GETAE-LAGEBES e o PPGE-UFES, sob nossa coordenação, buscou dar lugar a estudos e pesquisas sobre Políticas de qualificação da classe trabalhadora. Para além das ações de escolarização, esse número temático aglutinou análises sobre ações estatais e não governamentais coordenadas que, pretenderam dar respostas às pressões sociais e econômicas por preparação de trabalhadores para atuarem em postos de trabalho com alguma qualificação.

Em Trabalho-educação: uma unidade epistemológica, histórica e educacional, Maria Ciavatta (2017) assinala que o amadurecimento do campo da pesquisa em educação nos últimos anos nos permitiu avançar na busca do entendimento da unidade epistemológica do campo Trabalho e Educação. A constituição deste campo de pesquisa tem ajudado os pesquisadores a identificar um conjunto de questões relacionadas a fenômenos complexos como educação profissional, ensino técnico, educação tecnológica, educação de jovens e adultos trabalhadores, trabalho infanto-juvenil, movimento sindical, etc.

Fundada numa perspectiva histórico-social onde a luta de classes constitui a totalidade mais ampla da realidade, a história se coloca como método e como

\footnotetext{
${ }^{1}$ DOI: https://doi.org/10.22409/tn.16i30.p10324

${ }^{2}$ Doutor em Educação pela UFF. Professor na Universidade Federal do Espírito Santo (UFES). Membro do PPGE-UFES e coordenador do LAGEBES.
} 
processo de investigação da transformação social. Neste contexto, o Trabalho e a Educação tomados empiricamente como categorias distintas são indissociáveis e conceitualmente são pensados como Trabalho-Educação.

Para Ciavatta (2017, p.04), o “campo de pesquisa Trabalho-Educação busca pensar analiticamente e atuar socialmente sobre os processos educativos em sua relação com o mundo do trabalho". Segundo a autora os estudiosos "desse campo se identificam pelos estudos sobre o mundo do trabalho, mercado de trabalho, relações de trabalho, formação profissional, técnica e tecnológica, educação dos trabalhadores, formação integrada entre o ensino médio e educação profissional". Sua base teórica é "o pensamento crítico expresso pelo materialismo histórico". Neste sentido, é próprio "do campo de pesquisa Trabalho-Educação, no GT 09 da ANPEd, estudos sobre as relações capitalistas de produção, as transformações do mundo do trabalho, as políticas educacionais, o ensino médio, a preparação para o trabalho" (p.05).

A qualificação profissional, elemento central de análise no presente número temático, não pode ser tomada como processo desconectado do conjunto das contradições da luta de classe. Como bem nos informa Bravermam (1987), a formação profissional e a alienação do trabalho são forças em conflito no interior do processo produtivo que antecedem a forma exclusivamente escolar anterior a inserção produtiva.

A necessidade dos trabalhadores se qualificarem de modo sistemático decorre das formas históricas de elaboração e distribuição (alienada ou não) dos saberes profissionais que se articulam com o sistema da divisão social e técnica do trabalho. Estrutura essa atravessada pelas contradições de classe que se encontram no seio das disputas pelo controle dos saberes produzidos pelos trabalhadores e apropriados pelo capital. Nessa lógica o capital homeopaticamente por meio da escola tenta exercer controle do acesso dos trabalhadores aos saberes profissionais e conhecimentos outros, acumulados historicamente, cada vez mais complexos. Assim, uma leitura do campo Trabalho e Educação sobre as políticas de qualificação dos trabalhadores, considera a negatividade destas políticas, que ao escolarizar e 
profissionalizar promovem processos simultâneos de qualificação e desqualificação, conforme seus interesses econômicos e ideológicos.

Para designar o conceito de políticas públicas de educação situamo-nos na interface do campo da pesquisa em "Trabalho e Educação" e do campo da pesquisa em "Políticas Educacionais" ou "Estado e Educação".

No primeiro campo temos uma forte ênfase de base marxista que faz a crítica ao processo capitalista de produção e acumulação tendo em vista os fundamentos ontológicos de formação humana cujos objetos de pesquisa dão foco nas relações da educação média e profissional com as formas e relações de trabalho.

Já o campo acadêmico da Política Educacional, segundo Stremel (2016), caracteriza-se por estudos sobre a situação de ensino no país e estudos sobre a administração da educação, administração escolar e educação comparada (STREMEL, 2016, p.47); mas também vincula-se a certos interesses que estão em jogo, seja para legitimar uma determinada política, seja para negá-la, de tal modo que tomadas de posições dos intelectuais nesse campo podem contribuir para certos mecanismos de reprodução social (STREMEL, 2016, p.39).

Num esforço de conceituar a política como elemento central para designar sua derivação e especificidade no campo educacional, Stremel (2016) parte das distinções presentes na língua inglesa que elenca os conceitos de Polity, Politics, Policy (ou politicies). Para Stremel (2016), segundo os dicionários Pocket fowler's modern english usage e dictionare of the social sciences, Polity pode significar governo civil - constituição e ou sociedade - país, podendo ser utilizado de modo geral para designar sistema político como um todo (apud STREMEL, 2016, p. 64). Nesse caso Polity teria mais a ver com a estrutura do Estado. O termo Politics, por sua vez, segundo as obras de referência, teria nos conflitos e nos interesses em jogo, sua essência, referindose também às relações de poder presentes no Estado (Johnson Jr, 2003 apud STREMEL, 2016, p. 64).

De modo geral, o termo politics indicaria ações em conjunto de sujeitos que coletivamente articulados por meio de interações sociais, atuam nos processos de luta no interior do Estado. Já o termo Policy (ou no plural - Policies) diz respeito à ação pública dos governos, envolvendo intencionalidade e planejamento para 
realização de ações governamentais que se configuram como políticas públicas (Dutra, 1993 apud STREMEL, 2016, p. 64).

Nestes termos, podemos afirmar que a política tomada como estrutura ou sistema político e social (Polity) é produto de processos de interação social (Policy) relacionados às relações de poder e aos jogos de forças internas à luta de classes e frações de classe que disputam o controle do Estado (Polity) para fazer as políticas públicas (Politics) cujo alcance, consistência, racionalidade e intencionalidades, podem ser verificados segundo a sua afetividade. Esta, por sua vez, pode ser avaliada tantos pelos benefícios quanto pelos beneficiários (finais ou intermediários) sem perder de vista seus efeitos de curto, médio e longo prazo.

Nesta lógica, diferenciam-se as políticas estruturantes (políticas de Estado) das quais resultam infraestrutura e recursos perenes relacionados a serviços prestados pelo poder público e, as primeiras, como (políticas de governo), das quais resultam transferência de recursos financeiros que podem ficar no meio do caminho, beneficiando mais os operadores (beneficiários intermediários) dos serviços prestados do que o público-alvo (beneficiários finais). Tais princípios podem ser aplicados na avaliação dos "planos, projetos e programas" que se constituem como Politics de segunda categoria, identificáveis mais, como políticas de governo e de curto prazo. Historicamente, podemos identificar ações governamentais deste tipo.

Desde o governo de João Goulart, passando pela ditadura civil-militar, pelos governos FHC e Lula, chegando ao governo Dilma, foram instituídos muitos programas. Denominados de PIPMOI (Programa Intensivo de Preparação de Mãode-obra Industrial - decreto № 53.324 -18/12/63); PIPMO (Programa Intensivo de Preparação de Mão-de-obra - decreto № 70.882 - 27/07/72); PREMEM (Programa de Expansão e Melhoria do Ensino Médio - decreto no 70.067 - 26/01/72); PROMED (Programa de Melhoria e Expansão do Ensino Médio - parecer 15/98 do CNE e Resolução CNE/CBE ำ3/98); PROEP (Programa Nacional de Expansão da Educação Profissional - norma no 001/99 - 23/09/99); PLANFOR (Plano Nacional de Formação - lei nำ 7.998 - 11/01/90 e resolução 126/96 do CODEFAT); PNQ (Plano Nacional de Qualificação - resolução no 333 - 10/07/03); PROJOVEM (Programa Nacional de Inclusão de Jovens - no 11.129 - 30/06/05); PROEJA 
(Programa de Integração da Educação Profissional à Educação de Jovens e Adultos - decreto-lei no 5840 - 13/07/06; PROEMI (Programa Ensino Médio Inovador portaria MEC 971 - 09/10/09) e PRONATEC (Programa Nacional de Acesso ao Ensino Técnico e Emprego - lei no 12.513 - 26/10/11); estes, cumpriram papéis diversos, tendo ou não recursos externos, sendo determinados por acordos internacionais ou provindos de decisões internas.

Em geral, essas políticas derivam da iniciativa da União que, atendendo a determinadas demandas da "sociedade", estabelece linhas de ação por meio de repasse de recursos públicos às instituições não estatais e/ou por meio de uma ação direta das redes públicas (federal, estadual e ou municipal), que realizam determinado atendimento escolar. Essa dinâmica implica grande impacto nas políticas públicas de educação, estabelecendo um campo de disputa na luta pela hegemonia, no estabelecimento das prioridades educacionais nos planos financeiro, econômico, ideológico e pedagógico.

No campo educacional, esses programas podem deixar como legado obras realizadas, atividades de formação de professores, laboratórios e equipamentos instalados na estrutura escolar que podem resultar em benefícios de longo e/ou de médio prazo para a sociedade. Entretanto, quando as ações se resumem ao repasse de recursos do fundo público para o setor privado, esses resultados podem se reduzir à capitalização e ao fortalecimento de instituições e/ou de seus proprietários e dirigentes. Aqui, as consequências podem não resultar num legado educacional, podendo ainda fazer sobrepor os meios (contratação de entidades privadas) aos fins (atendimento ao públicoalvo).

Nesse contexto, a transparência e a fiscalização dos repasses e resultados são fundamentais para se avaliar a qualidade da efetividade do atendimento escolar.

Ao longo dos anos, muitas políticas públicas de qualificação articuladas ou não com processos de escolarização são colocadas em prática, tendo como base justificadora o argumento da falta de mão de obra qualificada e se inspiram nos princípios da teoria do capital humano com objetivo de impulsionar ou em decorrência do crescimento econômico. Exemplo disso é o documento "Exposição de Motivos" encaminhado à apreciação da Presidente da República à época, Dilma 
Roussef, classificando-o como um dos "maiores desafios colocados hoje para continuidade do crescimento econômico do País", que é a falta de mão de obra qualificada (BRASIL, 2011, p. 1).

Não obstante, as funções pretendidas pelos programas dessa natureza, em sua grande maioria, desarticulam-se dos processos mais amplos de escolarização, podendo também servir menos a objetivos estruturantes na repartição pública de oferta e permanência escolar, e mais a objetivos secundários no fortalecimento dos setores privados de formação profissional. Considerando que o fundo público deve financiar o direito à educação, o qual deve ser estruturado por meio de políticas públicas permanentes de modo a atender a todos os indivíduos universalmente e de forma obrigatória em ação direta e/ou colaborativa pelos entes públicos federados, cabe uma análise dos processos de formulação e implementação destas políticas.

No caso particular de projetos e programas tomados como políticas de governo e não de Estado, outras contradições se exacerbam devido ao caráter efêmero e não estruturante do conjunto de suas ações. Ou seja, consideramos, para efeito de nossa análise, que quanto mais imediatista for as premissas que orientam essas políticas, provavelmente mais distorções e inversões entre objetivos e resultados podem ocorrer. Assim sendo, as políticas que poderiam ser classificadas como políticas de Estado seriam aquelas estruturantes de um sistema nacional de educação no qual o setor privado teria apenas função complementar e não substitutiva já que, posto ser a educação um direito, perder essa essência significaria também perder o seu caráter público.

Nessa direção os textos em tela fazem a crítica necessária e oportuna articulando atual crise do capital na sua relação com o contexto de ampliação permanente do desemprego onde o Estado brasileiro, na maioria das vezes, ao invés de consolidar os direitos sociais, opta historicamente, por um processo de esvaziamento e de mercantilização da a educação desarticulando processos mais amplos de escolarização e de profissionalização da classe trabalhadora servindo a propósitos imediatos de gestão da pobreza, de reprodução do trabalho simples com políticas de formação aligeiradas voltadas não mais o emprego e sim para empregabilidade. 


\section{Artigos do número temático}

O artigo internacional, Uma abordagem interacional dos saberes e das culturas profissionais, de Telmo H. Caria (Portugal) e Marise Ramos (Brasil), aborda o conceito de saber profissional no âmbito das Ciências Sociais vinculado com o tema das culturas profissionais. Neste trabalho, considera-se "contribuições da microssociologia, vindas da fenomenologia social e do interacionismo simbólico, em diálogo interdisciplinar com as Ciências Cognitivas e com o pensamento histórico-dialético" para se discutir o complexo processo de produção do conhecimento e sua importância. A contemporaneidade do estudo nos leva a necessidade de repensarmos os elementos sociais e cognitivos constitutivos da ontologia do Trabalho.

O artigo Políticas de EJA no IFES: percursos de escolarização, de profissionalização e de resistência no PROEJA, de Edna Castro de Oliveira e Maria José de Resende Ferreira, com base em dados de registros das práticas de construção coletiva dos cursos do Proeja no campus Vitória "indicam que mesmo num contexto adverso à oferta da EJA na instituição, a ocupação dos cursos pelos trabalhadores evidencia marcas de resistência na manutenção da oferta" da modalidade EJA "e o exercício coletivo dos sujeitos na luta pelo direito à educação". Nesta pesquisa as autoras extremamente engajadas na defesa do direito dos jovens e adultos na rede federal, destacam o papel da pesquisa na construção coletiva para o processo de resistência que explica a expansão e o fortalecimento da oferta do Proeja no campus Vitória do IFES.

O artigo Educação Profissional: uma análise sobre a oferta de cursos técnicos, como ação do Programa Brasil Profissionalizado, nos estados da Bahia e do Acre, de Remi Castioni, contempla um estudo descritivo sobre a oferta de educação profissional nesses mesmos estados. Esse texto, dá notícia de um importante subprograma cujos objetivos estruturantes que visavam financiar a ampliação das redes estaduais de educação profissional poderiam e deveriam ter sido ampliados nos governos Lula e Dilma, mas que ficando subordinado ao Pronatec ainda permanecem pouco analisado. 
O artigo $A$ educação no período da ditadura militar: o ensino técnico profissionalizante e suas contradições (1964-1985), de Nara Lidiana Silva Dias Carlos, Ilane Ferreira Cavalcante e Olívia Morais de Medeiros Neta, por meio de um estudo de revisão bibliográfica e documental analisou as mudanças educacionais ocorridas durante o período da ditadura civil militar (1964-1985) para evidenciar não apenas a função social e ideológica das reformas viabilizadas pelas Leis no 5.540 , de 28/11/1968 (ensino superior nacional) e no 5.692 de 11/08/1971 (ensino de 20 profissionalizante), mas sobretudo revela a relação de subordinação entre elas.

O artigo O Projovem Urbano como política de invisibilidade da classe trabalhadora, de Rafael de Lima Bilio e Sonia Maria Rummert trata, à luz do materialismo histórico, analisa o programa denominado ProJovem Urbano, que visou atender jovens com idade entre 18 e 29 anos, alfabetizados, mas que não concluíram o 9 ${ }^{a}$ ano do Ensino Fundamental. Para os autores, trata-se de uma das muitas políticas focais de gestão da pobreza na qual, apesar dos avanços dos governos Lula-Dilma, foram mantidos os pilares neoliberais da política macroeconômica e muitos programas compensatórios de atenuação do desemprego e amortização de conflitos instituídos, como o Projovem urbano.

Compondo conjunto de análises, dando ênfase ao contexto mais recente, apresentamos 03 artigos: 1) Qualificação Profissional no Pronatec e as demandas do Neodesenvolvimentismo Lulo-Petista: formação voltada para a empregabilidade, de Ricardo Afonso Ferreira de Vasconcelos e Mário Lopes Amorim; 2) Pronatec: ampliação das ações fragmentárias e intensificação da privatização da formação do trabalhador, de Jaqueline Pereira Ventura, Ludmila Lustosa Lessa e Samantha Castro V. de Souza, e; 3) A trajetória do

Pronatec e a reforma do ensino médio: algumas relações com a política de educação profissional mundial, de Danilma de Medeiros Silva, Dante Henrique Moura e Lincoln Moraes de Souza.

Cada texto, ao seu modo particular, analisa aspectos problemáticos e contraditórios deste programa que envolveu vultosos recursos (cerca de 15 bilhões) e mobilizou enormes contingentes de estudantes (cerca de 10 milhões), em cursos realizados em todos estados da federação. O programa surge para resolver um suposto apagão de mão de obra, o que exigiria ampliação das redes físicas de 
educação profissional; com efeito, acabou por ser uma estratégia de coalizão política de afirmação como marca do governo Dilma (VASCONCELOS e AMORIM). Os processos educativos realizados caracterizaram-se por propiciar uma formação fragmentada para o trabalho simples e resultaram na intensificação do processo de privatização da formação do trabalhador (VENTURA; LESSA; e SOUZA). Além disso, afirma-se que o Pronatec representa um ponto de continuidade com a Reforma do Ensino médio que aprofunda ainda mais a dualidade estrutural da educação (SILVA; MOURA; SOUZA).

\section{Artigos de demanda contínua}

Nesse número da revista "Trabalho Necessário", como de praxe, foram publicados quatro trabalhos de demanda contínua que mantém nos seus temas e nos sujeitos das pesquisas correlação com a questão da inserção no mundo do trabalho.

A juventude trabalhadora do campo e da cidade vivencia, de modo particular, processos de qualificação profissional e de escolarização que nem sempre garantem uma formação humana emancipatória, capaz de Ihes trazer uma inserção profissional para além do trabalho simples e precário. Para tanto, sugerimos a leitura dos artigos: A condição de vida e as expectativas de jovens do campo e da cidade frente ao trabalho, à educação e ao futuro (Adriana D'Agostini e Rafael Márcio Kreutzer) e, A relação estabelecida entre a formação profissional e o ensino regular: falam os jovens aprendizes (Angelita Oliveira Almeida e Inara Barbosa Leão).

Destacam-se aqui, ainda, as experiências e estruturas públicas de formação propiciadas pelos casos analisados da rede pública de educação profissional da Bahia e da Escola Joaquim Venâncio - Fiocruz que, num cenário de regressão pública e privada das ações de qualificação, dão a ver alternativas públicas de formação humana. Para tanto evidenciamos os trabalhos: Educação Profissional Integrada na rede Pública Estadual da Bahia: a experiência do Centro Territorial da região Metropolitana de Salvador/BA (Aline de oliveira Costa Santos e Avelar Luiz Bastos Mutim) e Formação para a reforma psiquiátrica: a experiência do curso de qualificação em saúde mental para profissionais com 
formação de nível médio - EPSJV/FIOCRUZ (Nina Soalheiro dos Santos e Danúbiah Mendes Pereira).

\section{Teses e Dissertações}

No item "Teses e Dissertações" temos dois importantes trabalhos: A dissertação de Mestrado de Luiz Augusto de Oliveira Gomes intitulado: Jovens trabalhadores-estudantes: a construção da vontade coletiva em experiências de ocupação de escolas e a tese de Doutorado de Carlos Roberto Horta denominada Mutirão, Trabalho e Formação Humana: forjando novas relações entre o saber e o poder.

No primeiro trabalho, Gomes dialogando com Gramsci, Makarenko, Pistrak e Shulgin nos mostra como recentes processos concretos de luta, materializados nas ocupações dos estudantes, são capazes de produzir novos processos educativos emancipatórios e contra-hegemônicos. Num momento de grandes retrocessos nos direitos à educação, esse trabalho evidencia a força educativa dos movimentos sociais sem perder de vista os elementos teóricos revolucionários socialistas que Ihes dão base.

No segundo texto, Horta revisita as experiências de qualificação profissional da classe trabalhadora desenvolvida pelos próprios trabalhadores e militantes de movimentos sociais nos anos 1980. Na articulação entre formação sindical, profissional e política o trabalho destaca o papel do "operário como sujeito educador e elaborador de sua própria cultura" onde o espaço da fábrica para além do locus da alienação e de extração de mais-valia revela-se como espaço social "de atividade política, de educação e de tomada de consciência”. Diante da hegemonia do Sistema S na operacionalização das políticas de qualificação, Horta afirma que essas experiências são mais "avançadas do que a das organizações patronais, como o SENAI e o SENAC", pois pela sua proposta de uma educação operária constrói um saber (e um poder) que subverte o que fora definido e articulado a partir do poder do patronato sobre os trabalhadores.

\section{Memória e Documentos}

Na seção "Memória e Documentos" temos a icônica e rara imagem do presidente João Goulart ainda no exercício legítimo de suas funções. Para 
refletirmos sobre este contexto, Francisco José da Silveira Lobo Neto nos oferece a análise O Programa Intensivo de Preparação da Mão de Obra - PIPMO: Contexto Normativo. Nesta abordagem, ao dialogar com Cunha (2000) e Barradas (1986), o autor sinaliza alguns movimentos de reconfiguração do PIPMOI ao PIPMO que informam sobre o deslocamento da gestão do Ministério da Educação para o Ministério do Trabalho e forte influência e participação do Senai e do Senac.

Vem à tona, uma comparação inescapável entre Goulart e Roussef, ambos defenestrados do poder por meio de golpes conduzidos pelas elites nacionais do atraso que tanto em 1964 quanto em 2016, retiram do poder presidentes da república que tinham entre suas principais ações programas com vistas a "induzir o processo de desenvolvimento no Brasil" e integrando-se ao "processo mais global de acumulação, concentração e centralização do capital" (BARRADAS, 1986, p. 165 apud LOBO NETO) por meio de políticas de qualificação da classe trabalhadora como o PIPMO e o PRONATEC.

\section{Algumas considerações sobre a TN 30}

Não obstante, alguns aspectos positivos das Políticas de qualificação da classe trabalhadora, é possível perceber enorme incompletude do Estado Brasileiro que se articula com o esvaziamento do direito à educação. Os fundamentos dos interesses do capital ganham, nesta quadra histórica, ainda mais força no aprofundamento de crise de sua base civilizatória.

Como podemos perceber à luz dos textos e pesquisas presentes nesse número temático, os programas ao serem implementados operam priorizando ações de qualificação desarticuladas dos processos de escolarização com vistas à destinação de recursos para o setor não estatal de educação profissional, submetem-se à esfera privada na sua gestão ou execução, o que tende, por vezes, a distorcer objetivos republicanos presentes nas formulações que em geral propugnam a promoção do desenvolvimento econômico e a geração ou inserção do/no emprego.

Acreditamos que a educação gerida ou executada por instituições privadas ou ainda orientada para fins (intermediários ou finais) mercantis, pode servir a objetivos imediatistas que vão desde o viés economicista, visando formar profissionais adaptados ao mercado de trabalho, até o viés explicitamente mercantil, 
no qual a própria formação torna-se o mercado. Nesse caso, o fim intermediário subordina o objetivo final, em que se atribui mais importância à formação para o mercado do que o mercado da formação. Quando isso ocorre, a educação engendrase pela forma de mercadoria, atendendo aos ditames de fragmentação e flexibilização típicos do mercado, cujos princípios temporais e epistemológicos subordinam-se à mercantilização que corrói as bases curriculares do direito à educação.

Políticas como o Pronatec acabam por tentar eximir o poder público da responsabilidade com uma questão inerente ao capital que é o desemprego. A falta de empregos suficientes para todos é um aspecto estrutural do processo de produção de mais-valia que não será superado no interior do processo de acumulação capitalista. Tratando de planos nacionais de qualificação como o Planflor, PNQ e Pronatec, ideologicamente, tenta-se justificar, por meio do discurso da teoria do capital humano $(\mathrm{TCH})$ e da empregabilidade, que o Estado poderia reverter essa problemática e que tais políticas impactariam o desenvolvimento do país e / ou reduziriam as taxas de desemprego. Nessa lógica, a superação da condição de desempregado dependeria do empenho e da capacidade de adaptação dos principais afetados pela falta de oportunidades de trabalhos.

Nesse caso, evidenciam-se os objetivos ideológicos nos quais os programas de formação profissional não se adequam ao mercado, mas sim ao "não mercado", pois a ausência dos empregos em quantidade e qualidade inviabiliza a inserção dos egressos dos cursos, mas permite ao Estado responder às pressões sociais por crescimento econômico e por maior oferta de qualificação, entendida à luz da TCH como passaporte para o emprego.

$\mathrm{Na}$ verdade, esses planos de qualificação, além de serem usados como marketing político visam, por um lado, responder às pressões dos trabalhadores quando faltam empregos, gerando paz social e esperança aos desempregados, e por outro, dos empregadores quando faltam empregados. Ou seja por meio dessas ações o Estado capitalista, gera farta oferta de força de qualificação simples para o trabalho simples, mas com alguma atualização e em condições de reforçar o exército de reserva, mantendo os salários suficientemente baixos para o capital. 


\section{Referências}

BRAVERMAN, H. Trabalho e capital monopolista: a degradação do trabalho no século XX. Rio de Janeiro: Editora Guanabara, 1987.

CIAVATTA, M TRABALHO-EDUCAÇÃO: uma unidade epistemológica, histórica e educacional Autor: Niteri, Mimeo 2017.

STREMEL, Silvana A constituição do campo acadêmico da política educacional no Brasil Ponta Grossa: tese de doutoramento PPGE-UEPG, 2016.

Vitória, 13 de junho de 2018.

Publicado em: 21 de novembro de 2018. 